International Journal of Linguistics, Literature and Translation

ISSN: 2617-0299 (Online); ISSN: 2708-0099 (Print)

DOI: $10.32996 /$ ijllt

Journal Homepage: www.al-kindipublisher.com/index.php/ijllt

\title{
Chinese EFL Learners' Cross-cultural Pragmatic Competence: The Appropriateness of Request
}

\section{Yeboah Joyce 8 (D)}

Master student, Foreign Language and Applied Linguistics, Foreign languages and literature Department, Nanjing Tech University, China

$\triangle$ Corresponding Author: Yeboah Joyce, E-mail: joysyeb.jy@gmail.com

\section{ARTICLE INFORMATION}

Received: April 04, 2021

Accepted: May 10, 2021

Volume: 4

Issue: 5

DOI: $10.32996 /$ ijllt.2021.4.5.2

\section{KEYWORDS}

Request strategy, cross-cultural communication, pragmatic competence

\section{ABSTRACT}

The speech act of requesting has attracted a lot of attention in recent research. Previous studies reveal that conventionally indirect request strategies are commonly used by second language (L2) learners. This study is relevant because the findings would improve the requests strategies and its responses between Chinese EFL learners and foreigners. The study also examines the role of cross-cultural pragmatic competence in Chinese students in learning English as a Foreign Language (EFL) by considering the appropriateness of requests. It aims to find out the effects of knowledge of L1 culture on L2 pragmatic competence and how requests and its responses would contribute to pragmatic failure. The researcher used both quantitative and qualitative approach to analyse data. The data were collected through a discourse completion test (DCT) from 72 undergraduates and postgraduate students. The modified DCT was composed of two parts. The first was mainly concerned with the demographic information of the participants and second was composed of 12 simulated situations eliciting the appropriateness of requests in various communication settings. The findings of present study revealed that Chinese learners do not differ markedly from native speakers in their use of strategies, but do differ significantly in the formulaic expressions they employ for making the requests. Unclear request strategies and responses were identified as contributing factors to pragmatic failures. However, the study recommended that instructors should engage learners of English as a second language in a lot of appropriate request strategies to build learners' competence and ability to understand situations in different environments.

\section{Introduction}

This study takes it premise on the experience of most international students in the Nanjing Tech University. It was during the "Statistics for linguistics" class where my lecturer made a surprise request to me in the form of an invitation:

Lecturer: "Can we have dinner after class?"

Me: "Ok, that's fine!"

After this, I could clearly see the displeasure registered in his countenance. On our way to the venue for our dinner, he then asked me why I gave him such a response, instead of just saying "thank you."

I was also of the view that saying "Ok, that's fine" was a good way of accepting his request and then say thank you later, perhaps after the meal. This consequently became the subject of our discussion during our dinner. This chapter describes the background of the study, the problem statement, research objectives, and the importance of the study and how the study was organized.

\section{K C AL-KINDI CENTER \\ $\mathbf{R}$ D FOR RESEARCH AND DEVELOPMENT}

Your gateway to world-class research

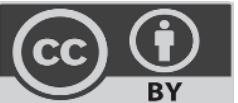

Published by Al-Kindi Center for Research and Development, London, United Kingdom. Copyright (c) the author(s). This open access article is distributed under a Creative Commons Attribution (CC-BY) 4.0 license 
The study of languages other than one's own can serve not only to help one understand what we as humans have in common but also to assist in the understanding of the diversity which underlines our languages' methods of constructing and organizing knowledge. Such understanding has profound implications with respect to developing a critical awareness of social relationships. Understanding social relationships and the way other cultures work is the groundwork of successful globalization business affairs. Cross-cultural communication is a field of study that looks at how people from differing cultural backgrounds communicate, in similar and different ways among themselves, and how they endeavour to communicate across cultures. Intercultural communication is a related field of study.

Cross-cultural communication endeavours to bring together the relatively unrelated fields of cultural anthropology with established areas of communication. At its core, cross-cultural communication involves understanding the ways in which culturally distinct individuals communicate with each other and also produce some guidelines with which people from different cultures can better communicate with each other. Communication failure often occurs when there is a conflict between two cultures. This, however, gives rise to cross-cultural pragmatic competence. Cross-cultural pragmatics (CCP) is arguably the subfield of pragmatics that draws the most attention in the modern world, where on a daily basis, participants interact while not sharing the same native or primary language for communication. Both comprehension and production of pragmatic meaning become quite complicated.

In the use of this mixed-methods study, a cross-cultural investigation on English requests applied by Chinese EFL graduate students in some universities has been undertaken. Request is a directive that embodies an effort on the part of the speaker to get the hearer to do something (Byon, 2004). To a very large extent, making requests in a foreign language can be said to facethreatening. This is because it demands the speaker to demonstrate considerable cultural and linguistic expertise. It is evident that breakdown in cross-cultural communication can simply be caused by inappropriate request strategies or the responses to such requests. When paying attention to Second Language Acquisition (SLA), different aspects of speech act of request could be explored in different language learning contexts, such as cross-cultural contexts (Blum-Kulka \& Olshtain, 1984), learning English as a Foreign Language (EFL), as in Ao (2005), learning English as a Second Language (ESL), as in Lin (2008), and Chinese (Zhang and Wang, 1997). So far these studies have contributed to the request literature in many different ways and have resulted in the creation and modification of the Discourse Completion Test (DCT), taxonomy and coding scheme of request (Blum-Kulka et al., 1984; Zhang \& Wang, 1997). Chapter two of this thesis discusses in detail these studies. However, studies on the role of instruction of politeness strategies for speech act realization in helping students achieve pragmatic appropriateness in their speech are still limited.

According to Blum-Kulka, "The motivational, intentional source of a request is the requestive goal, which speakers strive to achieve with maximum effectiveness and politeness" (p. 257). These goals may vary from the least coercive (e.g., requests for permission, information, and goods) to the most coercive (e.g., requests for action). A speech act of request is a prominent event in daily interactions, one in which the speaker usually manipulates appropriate linguistic forms to make requests according to certain situations. People produce requests for various reasons in everyday interactions, either to obtain information or a certain action, to seek support, or to acquire assistance from others; however, the way requests are presented varies from one speech community to another. In a request, the speaker to a greater or lesser extent imposes on the addressee hence there is a need to put politeness strategies into action in order to mitigate the imposition, in other words, to soften what the addressee might regard as an impingement on his/her freedom of action (Blum-Kulka, 1984).

The most effective way to perform a request is to be bluntly direct (e.g., "Give me the book" or "Close the window"). However, directness can conflict with politeness (Brown \& Levinson, 1987; Leech, 1983). Thus, from a sociolinguistic viewpoint, requests are considered FTAs (Brown \& Levinson, 1987) that place both the requester's negative face (his/her desire to remain unimpeded) and the requester's positive face (his/her desire for approval) at risk. The high social stakes of requests for both the speaker and hearer call for considerable "repressive action" or "face work" to make the request sound more polite and less imposing, typically through the use of mitigating devices that demand advanced pragmatic knowledge of the target culture on the part of the learner. Most studies have linked request and politeness as an effective way of improving cross-cultural pragmatic competences. Many studies have been conducted regarding appropriateness in request, politeness in request, realization of appropriateness and politeness in request across culture, and perspective on appropriateness and politeness in request across culture. Nevertheless, it is kind of rare studies to focus on both appropriateness and politeness in speech act, particularly request. Hence a study which is accordingly intended to find out the realization of speech act of request and the perspective of appropriateness and politeness across culture is urgently required.

The study sought to examine the role of cross-cultural pragmatic competence in Chinese students in learning English as a Foreign Language (EFL) by considering the appropriateness of request. The study will achieve the following specific objectives; 1. To find out the effect of knowledge of $L 1$ culture on $L 2$ pragmatic competence 
2. To examine how request and its response contribute to pragmatic failure.

\section{Literature Review}

\subsection{Cross-cultural communication}

Cross-cultural communication is a field of study that looks at how people from differing cultural backgrounds communicate, in similar and different ways among themselves, and how they endeavour to communicate across cultures. Intercultural communication is a related field of study.

Cross-cultural communication endeavours to bring together the relatively unrelated fields of cultural anthropology with established areas of communication. Cross-cultural communication requires an interdisciplinary approach. It involves literacy in fields such as anthropology, cultural studies, psychology, and communication. The field has also moved both toward the treatment of interethnic relations and toward the study of communication strategies used by co-cultural populations, i.e., communication strategies used to deal with the majority or mainstream populations.

\subsection{Cross-Cultural Awareness}

When dealing with the present globalized world, understanding the aspect of cultural and intercultural differences and similarities has to be one of the priorities to enable successful and fruitful communication between speakers from different countries. In order to have optimal cross-cultural interchanges, one should understand and respect foreign habits and traditions.

Focusing on the cultural aspect of the language and studying sociocultural interactions are not immature fields. There are many early fields of inquiry that dealt with cultural awareness; from those, we would like to highlight two: interactional sociolinguistics (Schiffrin, 1996; Tannen, 1992) and ethnographic microanalysis of interaction (Erickson, 1996; Garcez, 1993). These fields are interested in investigating cultural patterns of human communicative behaviour during social interaction.

When sociolinguistic competence is mastered, one would be able to select and sequence utterances or sentences to produce a coherent and cohesive discourse with a particular purpose in a specific situational context. However, Kramsch (1997) stressed that the foreign language learner should not aim to become an artificial native speaker but an 'intercultural speaker'. Intercultural competence is beset with several interrelated skills: attitude (open-mindedness and curiosity), knowledge (of social groups, their behaviour and life), the ability to relate and interpret (events or documents from different cultures), skills of interaction and discovery (ability to operate and acquire new knowledge of culture during real-time communication), and critical cultural awareness (ability to critically evaluate) (Byram, 1998). If culture is not taken into account, a number of misunderstandings may happen during international cooperation. This illustrates that there is a need for cultural and intercultural competence training. We defend that it is best for professionals to have such cultural business-like contact during their studies at the university.

\subsection{Request making}

Blum-Kulka (1991) described requests as being "pre-event" acts that intend to affect the hearer's behaviour as opposed to "postevent" acts such as apologies and complaints. According to Blum-Kulka, the motivational, intentional source of a request is the requestive goal, which speakers strive to achieve with maximum effectiveness and politeness. (p. 257). These goals may vary from the least coercive (e.g., requests for permission, information, and goods) to the most coercive (e.g., requests for action).

The most effective way to perform a request is to be bluntly direct (e.g., "Give me the book" or "Close the window"). However, directness can conflict with politeness (Brown \& Levinson, 1987; Leech, 1983). Thus, from a sociolinguistic viewpoint, requests are considered FTAs (Brown \& Levinson, 1987) that place both the requestee's negative face (his/her desire to remain unimpeded) and the requester's positive face (his/her desire for approval) at risk. The high social stakes of requests for both the speaker and hearer call for considerable "repressive action" or "face work" to make the request sound more polite and less imposing, typically through the use of mitigating devices that demand advanced pragmatic knowledge of the target culture on the part of the learner.

\subsection{General characteristics of request}

Blum-Kulka and Olshtain (1984) launched the term CCSARP (Cross-Cultural Study of Speech Act Realization Patterns) and subdivided these three levels into nine distinct sub-levels called 'strategy types' that together form a scale of indirectness. The categories on this scale are expected to be manifested in all languages studied; the distribution of strategies on the scale is meant to yield the relative degree of directness preferred in making requests in any given language, as compared to another, in the same situation.

The nine strategy types are: (1) Mood derivable, the grammatical mood of the verb in the utterance marks its illocutionary force as a request, e.g. "Clean up this mess" ; (2) Explicit performatives, the illocutionary force of the utterance is explicitly named by 
the speakers, e.g. "I'm asking you not to park the car here" ; (3) Hedged performative, utterances embedding the naming of the illocutionary force, e.g. "I would like you to give your lecture a week earlier" ; (4) Locution derivable, the illocutionary point is directly derivable from the semantic meaning of the locution, e.g. "Madam, you'll have to move your car" ; (5) Scope stating, the utterance expresses the speaker's intentions, desire or feeling the fact that the hearer do X, e.g. "I really wish you'd stop bothering $\mathrm{me}^{\prime \prime}$; (6) Language specific suggestory formula, the sentence contains a suggestion to $X$, e.g. "So, why don't you come and clear up the mess you made last night?" ; (7) Reference to preparatory conditions, utterance contains reference to preparatory conditions (e.g. ability or willingness, the possibility of the act being performed) as conventionalized in any specific language, e.g. "Could you clear up the kitchen, please?" ; (8) Strong hints, utterance contains a partial reference to object or to elements needed for the implementation of the act (directly pragmatically implying the act), e.g. "You've left this kitchen in a right mess" ; (9) Mild hints, utterances that make no reference to the request proper (or any of its elements) but are interpretable through the context as requests (indirectly pragmatically implying the act), e.g. "I'm a nun (in response to the persistent boy who keeps pestering her on the street)

\subsection{Theoretical Review on Requests}

Many scholars have investigated the realization of request across culture and they found that there were some variables that affect the realization of request. In terms of gender, Al-Marrani and Sazalie (2010:63) found that there was a general trend in Yemeni Arabic for higher levels of directness in male-male interaction and higher levels of indirectness in male-female interaction.

Lorenzo-Dus and Bou-Franch (2003:196-197) revealled at least two findings in their study involved Spanish and British undergraduates: both Spanish men and women used mainly direct strategies in their requests, and British women were not more direct than men. The requests strategies use is also influenced by the cultural background of society.

Zhu and Bao (2010:850) compared Chinese and Western politeness in cross-cultural communication. They found that in western society, personal interest, individual power, and privacy are all believed sacred and inviolable.

Tawalbeh and Al-Oqaily (2012:85) conducted research regarding indirectness and politeness in American English and Saudi Arabic requests. The results of their study revealed that conventional indirectness was the most prevailing strategy employed by the American sample. On the other hand, the Saudi sample varied their request strategies depending on the social variables of power and distance. Power and distance were also found as variables affecting the use of requests strategies (Han, 2013:1104). By contrasting the strategies of head acts both in English and Chinese, we can find that the similarity between native Chinese speakers and native English speakers is that both value conventionally indirect strategies and their difference lies in that native Chinese speakers prefer to use direct strategies i.e. imperatives, in some cases, while native English speakers seldom choose to use imperatives when requesting someone to do something. Ashoorpour and Azari (2014:39) found that there is a significant relationship between grammatical knowledge and pragmatic competence in pre-intermediate and intermediate level students. Those who were at an advanced level and had more grammatical knowledge performed better both in grammatical knowledge and pragmatic competence.

Requests are important to an L2 learner and they can be executed with several different strategies, including the direct, conventionally indirect and unconventionally indirect strategies, which will be presented in this paper. Lastly, they can include a wide variety of subtle implications of politeness, deference, and mitigation.

In relation to request strategies, Kılıçkaya (2010) did a study with Turkish EFL students where their pragmatic competence in using certain request strategies was investigated. More specifically, the focus was on the degree of their success in terms of the level of directness of their request strategies in various contexts. The results showed that the participants had linguistic means in order to operate pragmatically in different contexts while requesting. However, in situations requiring a certain level of politeness, their use of request strategies was not very satisfactory, according to the author. A suspected reason for this is the lack of effective language learning/teaching textbooks which do not provide much stimulation for the students' pragmatic competence (Kılıçkaya, 2010).

Another study conducted by Daskalovska et al. (2016) investigated the use of request strategies by EFL learners at an intermediate level of proficiency in the Republic of Macedonia. Data was collected by applying discourse completion tasks and role-plays, and then analysed with the help of Blum-Kulka et al.'s (1989) classification of request strategies. The result of the study implies that the most commonly used request strategies by Macedonian EFL learners are conventionally indirect strategies.

The choice of request strategy in a certain context is influenced by situational and cultural factors (Blum-Kulka et al., 1989; Kinginger, 2009) and different cultures generally agree on typical tendencies in relation to situational variation. For example, a more demanding request would generally be asked in a more indirect and polite manner as opposed to minor favor, such as 
asking a person to pass the salt. In interaction among friends, more casual requests would be employed, compared to requests from acquaintances, presuming that both situations regard the same request. On the other hand, the explicit, direct strategies appropriate for a certain situation may vary among different cultures (Blum-Kulka \& Olshtain, 1989)

\subsection{Request Study in Cross-Cultural Context}

The cross-linguistic and cross-cultural variation features of requests have necessitated a considerable amount of studies to be conducted regarding their realization patterns in different sociocultural settings. A typical example is the Cross-Cultural Speech Acts Realization Patterns (CCSAPP) by Blum-Kulka and Olshtain (1984) which facilitates academic investigations of the realization patterns of two speech acts, requests and apologies across different languages. Seven languages were incorporated into their study, namely Australian English, American English, British English, Canadian French, Danish, German, and Hebrew. 400 undergraduate students were used for Blum-Kulka et al.'s (1984) study. They were drawn from each of the seven countries, namely the U.S., Britain, France, Denmark, Germany, and Israel. All participants were freshmen or sophomores in some subject but linguistics. Half of the participants were native speakers and half non-native speakers of English. Data was collected through the Discourse Completion Test (DCT), which comprised incomplete discourse patterns eliciting requests to people with different social relationships, such as parents, policeman, or classmates. After data was collected, the researchers developed a coding scheme for analysing the speech acts under study. All request strategies were classified into three major categories according to the degree of directness, namely direct strategies, conventionally indirect strategies, and unconventionally indirect strategies. These were later coded into nine sub-strategy types. Blum-Kulka et al. (1984), held the view that direct request refers to those "syntactically marked as imperatives or by other verbal means that name the act as a request, such as performatives". Conventionally, the indirect request is realized by "reference to contextual preconditions necessary for its performance, as conventionalized in a given language" (i.e., Could you do it/would you do it?) Unconventionally indirect request is realized by "either partial reference to object or element needed for the implementation of the act" (i.e., Why is the window open?). Results obtained from their research indicated that the way and manner in which the expression of request was carried had to do mainly with the variety of languages and cultures, and a great deal of less proficiency displayed on the part of non-native speakers in applying non-conventionally indirect request strategies.

However, conventionally indirect request strategies seemed to be preferred by both native and non-native speakers of English in different countries (Blum-Kulka \& Olshtain, 1984). An investigation carried out by Ueda (2006) revealed how Japanese EFL learners used request strategies in interactive discourse and how their pragmatic competence saw a rise with increased English proficiency levels. Participants of the study were mainly intermediate-level Japanese EFL learners (Intermediate Low and Intermediate-Mid) and native speakers of American English who had been living in Japan for about one year as at the time of the study.

Role-play section of the Standard Speaking Test (SST) corpus was adopted in the data collection process with the three groups of participants, after which they were compared. According to Ueda (2006), since "the SST rates speakers' oral proficiency in English and not merely their grammatical competence, it is considered as the best method for evaluating the pragmatic development of learners". The researcher in this study revised the coding scheme according to Blum-Kulka et al. (1984). The findings indicated that Japanese EFL learners preferred to use conventionally indirect request strategies and that their ability to use indirect requests would increase as and when their English proficiency levels also increased. As to whether Japanese EFL learners preferred to use a wider variety of strategies as their English proficiency level increased was however not indicated.

Lower-level Japanese EFL learners, on the other hand, did not use more hints than the higher-level learners did. Fukushima (1996), unlike Ueda (2006), carried out a comparative study of request strategies in British English and Japanese. Two Situations with different degrees of imposition were used in this study and in order to make a more precise evaluation on the imposition of the request, the factors of social distance and relative power of the speaker and hearer were set as equal in these two situations.

In addition, the request situations were also considered similar to the cultural perspective. Participants selected for this study were made of 16 British undergraduates and 15 Japanese undergraduates, who were compatible with age, level of education, and occupation. Cards on which request situations were written in their native languages were first presented to the participants. Then they were expected to respond to these situations in their native language. All the responses were tape recorded. Data were analysed by the coding scheme developed by Blum-Kulka et al. (1984). In order to cater to the characteristics of the participants, additional modifications were made by the researcher, such as adding more categories or defining each category for the Japanese participants in Japanese. The focus of the analysis was the structure of the head act and supportive moves. As explained in Blum-Kulka et al. (1984), the head act of the request is the part of the sequence which might serve to realize the act independently of other elements (i.e., Could you do it?). Supportive moves refer to those address terms to the hearers or explanations for making the request (Blum-Kulka et al., 1984). Results indicated that, for both British and Japanese participants, the higher the degree of imposition of the request, the more indirect the request strategies applied. However, compared with 
the British participants, the Japanese participants used less supportive moves and their expressions were more direct and straightforward. This result was not consistent with that discovered by Ueda (2004).

Hassall (2003) conducted a comparative study of requests between Australian learners of Indonesian (learner subjects) and Indonesian native speakers (native speaker subjects). The learner subjects included 20 Australian students undertaking their second or third year of an undergraduate degree program in Bahasa Indonesian. The native speaker subjects were 18 students enrolled in a degree program in a range of disciplines at an Australian university. The majority of the native speaker subjects came from the main island of Java, and none of them had been in Australia for more than three years. Interactive oral role play, through which the participants communicate with a native Indonesian speaker in a given situation and a written cue was the means through which data was collected. Each student was tasked to perform 12 to 13 of the total of 24 situations, as well as a number of non-request (distractor) situations. All the role plays were audio-recorded. Analysis of data was done according to the coding scheme developed by Blum-Kulka et al. (1984). Results obtained and their subsequent analysis indicated that the learner subjects made a larger proportion of direct requests than the native speaker subjects. This type of request strategy consisted of more than one-quarter of the overall requests by the learner subjects (Hassall, 2003).

The second finding of the study indicated that both learner subjects and native speaker subjects preferred to use conventionally indirect request strategies in conversations (over 40 percent). However, According to Yang (2009) citing (Hassall, 2003), no contrastive differences were discovered between these two groups of learners in the selection of the request strategy types when the situation changes.

\subsection{Request Studies in EFL and ESL Contexts}

Quite a number of investigations into the speech act of request have been conducted in an EFL context in China. In an attempt to discover how Chinese college students make the English speech act of request, Ao (2005) conducted research on a group of non-English major undergraduate students in China. She designed an open-ended DCT with four Situations. The purpose of her study was to investigate the characteristics of three components of the request, namely alerters (i.e., addresses), head acts, and supportive moves. Results gathered from the research showed that the composition and sequence of the request were greatly influenced by social power and the degree of difficulty of the request.

When there are a speaker and an interlocutor on equal social status, seldom will they use supportive moves in making the request, and their alerters are much diversified. When the speaker is in a relatively lower social position to the hearer, the alerters mainly focus on "Excuse me" and Sir/President/Manager/Mr", whereby the speaker uses various supportive moves in expressing respect to the hearer $(\mathrm{Ao}, 2005$,$) . Aside from the influence of social power, the request strategies the students use are sometimes$ influenced by the degree of difficulty of the request. Maintaining social distance and social power as constant, the evidence is that, the more difficult the request, the more diversified the supportive moves used in making the request.

The study of English requests was also carried out on Japanese EFL learners by Reinbold in 2004. In the study, 10 Japanese EFL learners whose TOEFL scores were all above 600 were used together with five American English speakers as informants. All participants were resident in Japan. Similar to the study by Hassall (2003), the method used to collect data was an oral role play where participants were expected to respond verbally to a DCT questionnaire. 10 request eliciting situations were designed for the study.

The social status of the hearer and the imposition of the request were the two variables incorporated in the design of the questionnaire. In the situations on the questionnaire, participants were expected to make either high-imposition or lowimposition requests to people of three levels of social status: higher, equal, and lower. Reinbold (2004) made use of two coding schemes for the data analysis: one is Takahashi's (1993) indirectness level of taxonomy (cited in Reinbold, 2004), and another is Blum-Kulka's CCSARP (1984).

Consequently, similar results were obtained by using these two coding schemes: It could be seen that American English speakers were more direct than Japanese EFL learners when making low imposition requests to listeners of equal status. However, they were more indirect when making low-imposition requests to listeners of lower status. For medium- and high- imposition requests, no matter the status of the listeners, whether lower or equal, Japanese EFL learners were seen to be more indirect than the American English speakers in the request making process. When speaking to a stranger, an American English speaker was more direct than Japanese EFL learners.

Different from the previous quantitative research design, Lin (2008) carried out a qualitative study which compared the speech act of requests and compliments between five Chinese graduate students and five native English speakers in a British university. The purpose of Lin's study was to investigate the pragmatic failure committed by Chinese students in trying to express requests and compliments in intercultural communication settings. Chinese students were asked to respond to a written DCT composed

Page | 25 
of five different situations involving compliments and requests. The native English speakers' responses were regarded as a baseline to evaluate the quality of Chinese students' responses. After their completion of the DCT, a follow-up semi-structured interview was conducted among the Chinese students in order to elicit "talk about their real experiences as foreigners in real-life interactions with native speakers" (Lin, 2008). Data analysis of the speech act of request was based on the request taxonomy made by Blum-Kulka, et al. (1984). Results gathered from Lin's research showed some consistency with those of Blum-Kulka (1984) this is because both Chinese students and native speakers employed conventionally indirect strategies. However, their ways of expressing the requests were slightly different from each other.

Chinese students displayed less capability in the use of more complex syntactic structures to mitigate the degree of request. For example, when using more sentences like "Could you...?" or "Can I...?" when they spoke to their teacher compared to "Would you mind if...?" or "Is there any chance that I could...?" by native English speakers (Lin, 2008). Lin (2008), was able to conclude that, although Chinese students could respond to the situations with relatively appropriate request strategies, they sometimes failed in their real-life experiences. An example is seen when a student reported that she said "Stop, stop" directly to a taxi-driver when she expected the driver to drop her off at a particular place instead of applying more polite and indirect request strategies (Lin, 2008).

\subsection{Request Study in Chinese and Other Languages}

The results obtained from the study carried out by Blum-Kulka et al. (1984) was also evidenced by Zhang and Wang (1997) in an attempt to discover how request strategies reflected in the Chinese setting. 100 participants from various backgrounds were investigated. They included among others as college teachers, students, and doctors. The research instrument employed by these researchers was a modified DCT with different social situations.

The closing sentence in the conversation was intentionally deleted to allow the participants to freely express their opinions without any situational constraints. Their findings showed that Chinese speakers considered the conventionally indirect request as the most appropriate strategy in expressing politeness. Brown and Levinson (1987) were of the view that a speaker's request strategy was highly influenced by three social variables, these are social distance, social power, and imposition of request. Social distance has to do with the degree of familiarity between the speaker and the hearer; social power, on the other hand, refers to the power or status of the hearer which is relative to the speaker; and a degree of imposition which refers to the degree of difficulty in fulfilling a request in a certain social context.

Zhang and Wang's (1997) study indicated a positive correlation among the three social variables with the directness of request strategies. From a socio-pragmatic perspective, Hong (1996) related a study conducted on the Chinese request strategy to Chinese language teaching in order to find more suitable instructional methods in teaching Chinese as a foreign language. Participants for the study were made up of two groups of American college students; 12 of which had home exposure to Chinese and eight had no such exposure. All of them were Americans and they had learned Chinese for four semesters. The DCT that was used for the research was composed of five close conversations concerning campus and college life.

Participants were expected to initiate a conversation according to a situation and provide a closing sentence to the conversation. Analysis of collected data indicated that students with home exposure to Chinese (HEC) did not make any non-accessible request, while students with non-home exposure to Chinese (NHEC) made a considerable six percent of them. Sun and Zhang (2008) believed that Hong (1996) failed to include a cross-linguistic comparison between native Chinese and American students although she discovered that American students' pragmatic competence was somewhat influenced by their social and cultural background.

To ascertain the differences and difficulties that American students encountered while learning Chinese, a group of 12 native Chinese graduate students and eight American undergraduate students were used in a comparative study by Sun and Zhang (2008) on the directness of Chinese request strategies. The instrument used in their study was a modified DCT, which was composed of eight request eliciting situations. Participants were asked to respond to situations with an appropriate request.

Analysis of the data collected from the study made them conclude that, although both native Chinese and American students applied more conventionally indirect request strategies than direct and nonconventional request strategies, the percentage used by American students was much higher than that of the native Chinese. However, Sun and Zhang (2008) discovered that American students demonstrated less capability in adjusting their request strategies whenever the social distance and power relationship between the hearers were changed.

Felix-Brasdefer (2005), in a similar study to that of Ao (2005), also studied the indirectness and politeness of Mexican requests from a discourse level. Participants of the study were made up of 10 native speakers of Mexican Spanish students who were 
studying at an American university as part of a study abroad program. Open-ended role play questionnaire, with five experimental and five distractor items, was used to collect data. Each participant was expected to role-play the situations verbally with two native speakers of Mexican Spanish. All role plays were tape recorded. Among the factors considered while designing the experimental situations were; level of familiarity and the power relationship with the listener. Request strategies were coded using Blum-Kulka et al.'s (1984) request coding manual. Repeated-measures analysis of variance (ANOVA) and paired t-test were used to analyse the data collected. Analysis of results indicated that the means of strategy which was used was significantly different across the five situations. Among the three types of request strategies, conventionally indirect request strategies were the most frequently used, followed by direct requests. A lower preference was given to the use of non-conventionally indirect requests.

In an addition made by Harlow (1990) to the knowledge base of the speech act of request realization patterns in French, she conducted a study which compared the similarities and differences of the speech act strategies for request, thanks, and an apology. Among the factors considered for her research were age, sex, and familiarity with the addressee on the realization of these speech acts. A questionnaire with written role-play situations was designed and used as the method of data collection. Participants of the study were drawn from 28 native speakers of French and 32 non-native speakers who were enrolled at an American university. The demographic data analysis indicated that the participants' ages ranged from 19 to 39 , with 25 as the mean age for the natives and 22 the mean age for the non-natives. A gender disparity existed between these two groups, for 61 percent of the native speakers were males and 84 percent of the non-native undergraduates were females. Paired t-tests were used to compare the mean number of words used by the two groups of speakers.

Results from the data revealed that age was an important factor which influenced the choice of request strategies. Indirect requests were applied with older strangers instead of the younger addressees. According to Harlow (1990), this partly reflected "the French value system of respect for their elders manifested by the use of a higher degree of politeness" (p. 347).

Familiarity with the listener is another important factor that affected the length of the statements used for making requests. Barron (2016), also delved into Developing Pragmatic Competence Using EFL Textbooks: Focus on Requests.

\section{Methodology \\ 3.1 Research Questions}

The purpose of the present study is to find answers to the questions "does knowledge of L1 culture affect L2 pragmatic competence?" Secondly, do a request and its response contribute to pragmatic failure? This present study will seek to analysis the L1 cultural effects on Chinese Learners' responses to request. How Chinese English learners transfer pragmatic competence from their local language speaking skills and give an appropriate response to request. The study will also consider how a request and its response contribute to Chinese learners' pragmatic failure.

\subsection{Research Design}

This study combines the quantitative and qualitative approach of analysing data. It is fundamentally a qualitative research. In this study, I applied a mixed methods research design in data collection. According to Creswell and Clark (2007), mixed methods research is "a research design with philosophical assumptions as well as methods of inquiry" (p. 5). As a method, it is designed to collect and mix both quantitative and qualitative data in the research study. As stated in Creswell and Clark (2007), "Its central premise is that the use of quantitative and qualitative approaches in combination provides a better understanding of research problems than either approach alone" (p. 5). According to Mertler and Charles (2008), any research that produces a narrative data or verbal descriptions and opinions is called a qualitative research, and the kind of research that produces mostly numerical data (i.e., scores and measurements) is called a quantitative research. Each approach has its merits and demerits. Qualitative research is advantageous in that it can be used to explore the distinctiveness and uniqueness of situations of individuals in specific social and cultural settings.

This advantage, however, can equally be a pitfall because it may focus so much on individual results and fail to make connections to the whole target population. Comparatively speaking, quantitative researchers are able to make generalizations across populations in large scale research, but they may fail to respond to individual differences in specific social and cultural settings. In order to avoid the weaknesses of applying either a quantitative or qualitative approach, I applied a mixed methods research design, which is explanatory in nature. According to Creswell and Clark (2007), the explanatory design is a two-phase mixed method design, in which the qualitative data explains or builds upon the quantitative data interpretation and results. Geluykens (2007) suggests methodological triangulation, "the use of multiple methods to measure a single construct". Notwithstanding, the eventual methodological objective should not be simply to combine data triangulation and methodological triangulation, but "to integrate these two methodologies within a single research program" (Geluykens, 2007) 


\subsection{Discourse Completion Test}

Prior to conducting the present study, I obtained permission from my supervisor to use his class to conduct a pilot study. The instrument used for collecting quantitative data in this study is a questionnaire, a modified Discourse Completion Test (DCT), which was designed by referring to Blum-Kulka et al. (1984) and Sun and Zhang (2008). DCTs are "written questionnaires including a number of brief situational descriptions, followed by a short dialogue with an empty slot for the speech act under study" (Kasper \& Dahl, 1991, p. 9). The widespread use of the DCT as a data-collection method began after its broad use in the Cross-Cultural Speech Act Research Project (CCSARP), which compared the speech act behaviors of native speakers of a variety of languages with the behaviour of learners of these languages. Most DCTs are either closed or open-ended. Although both formats require participants to read each situation, whether in their native or second language, before writing the response they think fits the given context, the formats differ in the presence or absence of the hearer's response (i.e., a rejoinder). In a closed format, originally used by Blum-Kulka (1982) and in the CCSARP, the discourse is structured by providing a space for the speech act followed by a rejoinder.

The modified DCT was composed of two parts. Part one was mainly concerned with the demographic information of the participants, such as their age, gender, and level of education. An additional section was added for Chinese students to indicate whether or not they have had English lessons outside their normal school sessions and also to say whether they have ever travelled to an English speaking country.

Part Two is composed of 12 simulated situations eliciting the appropriateness of requests in various communication settings. (See Appendix A). After each situation, a form of request was stated for participants to evaluate its appropriateness in the given context. Further, participants were expected to indicate their personal request strategy should they find themselves in a similar situation and finally state their reasons briefly. For example, participants were expected to select the most appropriate form of request from the given options: "totally acceptable", "acceptable", "totally unacceptable", "unacceptable", and "uncertain"

The rationale for modifying Blum-Kulka et al.'s (1984) DCT into an open-ended questionnaire was to elicit responses more similar to naturally occurring conversations. In order to state the situation as clearly as possible, more descriptive sentences were added into the scenario. All scenarios in the modified DCT were anticipated to elicit participants' perceptions on the relationship with different types of people, including faculty, students, friends, staff, and parents. For example:

\section{Example 1}

At the airport. You have just arrived in London. You are at Heathrow Airport and want to find out the fastest way to get to the city centre. You see a police officer who can help you, so you ask: Excuse me. I have just arrived from Spain and I would like to know the fastest way to get to the city centre. Would you mind helping me, please?

\begin{tabular}{|l|l|l|l|l|}
\hline Totally acceptable & acceptable & uncertain & Unacceptable & $\begin{array}{l}\text { Totally } \\
\text { unacceptable }\end{array}$ \\
\hline & & & & \\
\hline
\end{tabular}

Example 2: In the dormitory. Your roommate who is from Australia shows you a new wrist watch he bought a few days ago. It appears to be quite expensive, after having a look at it, you want some details of it, and what would you say? : Wow it's a cool wrist watch, tell me more

\begin{tabular}{|l|l|l|l|l|}
\hline Totally acceptable & acceptable & uncertain & Unacceptable & $\begin{array}{l}\text { Totally } \\
\text { unacceptable }\end{array}$ \\
\hline & & & & \\
\hline
\end{tabular}

\subsection{Data collection}

Prior to the study, I conducted a pilot study with seven Chinese graduate learners and five international graduate students in order to refine the questionnaire and to elicit the framework for the simulated situations. The process of the pilot study included questionnaire distribution on the spot. After the participants completed the questionnaire, I interviewed six of them, including three Chinese and three international students whose official language was English. The questionnaire was modified according to the participants' suggestions. To see whether the modified version of the DCT was appropriate or not, I redistributed it to a different set of Chinese graduate students for another on the spot completion. No other suggestions were made.

The questionnaire was sent to wechat platforms of respondents and online survey. First, the researcher made little introduction and purpose of the survey. The researcher assured the participants of keeping their responses confidential. The purpose of the 
questions was described briefly and enough time was given to the respondents to answer the questions. With the first delivery of the questionnaire online, I obtained 42 responses. After successful second delivery, 30 more responses were added. A total of 72 respondents participated in filling the questions.

\subsection{Data Analysis}

The coding scheme for the questionnaire response analysis in this study was developed, ranging from totally acceptable 5 , acceptable 4, uncertain 3, unacceptable 4 and totally unacceptable 1 . The results were analysed both qualitatively and quantitatively. The quantitative aspect was illustrated using bar charts to show the degree of responses from the respondents.

In order to increase the validity of the present study, in coding the appropriateness of the request strategies, I also found five international students whose official language was English to serve as co-raters. I was fortunate enough to get one American lecturer who was a proficient English linguist, so his rating was considered as the main reference for analysing the results. When there was a difference in the rating assigned to a particular sentence, the study would select the one that was agreed on by at least two of the co-raters. If no agreement was reached among all raters, it would rely on the proficient linguist for the deciding point.

\section{Results}

The survey revealed that the males were $64 \%$ and the females were also $36 \%$. Also, with the age of the respondents, the survey revealed that $47 \%$ were within the age range of $18-25$ years, 31\% were from 26 to 30 years, $15 \%$ were between $31-35$ years and $7 \%$ of the respondents were above 35years. The highest age range among the respondents was 18 years to 25 years which was $47 \%$. This was followed by 26 years to 30 years and it represents $31 \%$ of the respondents. The study also explores the level of the respondents' background. It was found that the undergraduates were $33 \%$ whilst the postgraduates were also $67 \%$. More graduates were represented than undergraduates.

The study sought to know whether respondents had ever participated in learning English outside the education system. 26 of the respondents who represent $36.1 \%$ said they have participated in different English learning classes whilst 46 of the respondents who represent $63.9 \%$ responded no. Most of the respondents who said 'yes' have attended private classes, English training centre, online teaching, individual learning and others before.

From the survey, 27 of the respondents who represent $37.5 \%$ argued that they have travelled to an English speaking country whilst 45 of the respondents representing $62.5 \%$ said "no". Therefore a majority of the respondents have not been to any English speaking country.

Table 4.1 shows inferential statistics on education. The output is from the independent t-test Levene's Test of Equality of Variances. An assumption of the independent t-test is that the two groups you are comparing have a similar dispersion of scores (otherwise known as homogeneity or equality of variance)

Table 4.1: Independent Samples T-Test for level of education

\begin{tabular}{|c|c|c|c|c|c|c|c|c|}
\hline \multicolumn{2}{|c|}{$\begin{array}{l}\text { Levene's Test for Equality of } \\
\text { Variances }\end{array}$} & \multicolumn{7}{|c|}{ t-test for Equality of Means } \\
\hline \multirow[t]{2}{*}{$\mathrm{F}$} & \multirow[t]{2}{*}{$P$} & \multirow[t]{2}{*}{$\mathrm{t}$} & \multirow[t]{2}{*}{$d f$} & \multirow[t]{2}{*}{$\begin{array}{ll}\text { Sig. } & (2- \\
\text { tailed }) & \end{array}$} & \multirow[t]{2}{*}{\begin{tabular}{|l} 
Mean \\
Difference
\end{tabular}} & \multirow[t]{2}{*}{\begin{tabular}{|ll} 
Std. & Error \\
Difference &
\end{tabular}} & \multicolumn{2}{|c|}{$\begin{array}{l}\text { 95\% Confidence Interval of the } \\
\text { Difference }\end{array}$} \\
\hline & & & & & & & Lower & Upper \\
\hline 6.805 & .011 & \begin{tabular}{|l|l|}
1.249 \\
\end{tabular} & 56.290 & .217 & .14381 & .11514 & -.08682 & .37444 \\
\hline
\end{tabular}

In the table 4.1, variances cannot be assumed to be equal as the $F$-value is significant $(F=6.81, P=.011<.05$. The assumption of homogeneity of variances is not met. This indicates that there are statistically significant differences between undergraduates and postgraduates in education $t(56.29)=1.25, p=.217>.05,95 \% \mathrm{Cl}[-0.09,0.37]$

\subsection{Quantitative Analysis of results}

Quantitative study results are presented based on the questionnaires. Both descriptive statistics and inferential statistics were applied in analysing the questionnaire responses collected from the participants. The respondents rated the request strategies with respect to each scenario to determine whether the request strategy is acceptable or unacceptable. 
Figure 4. 1 Could you pay for my coffee?

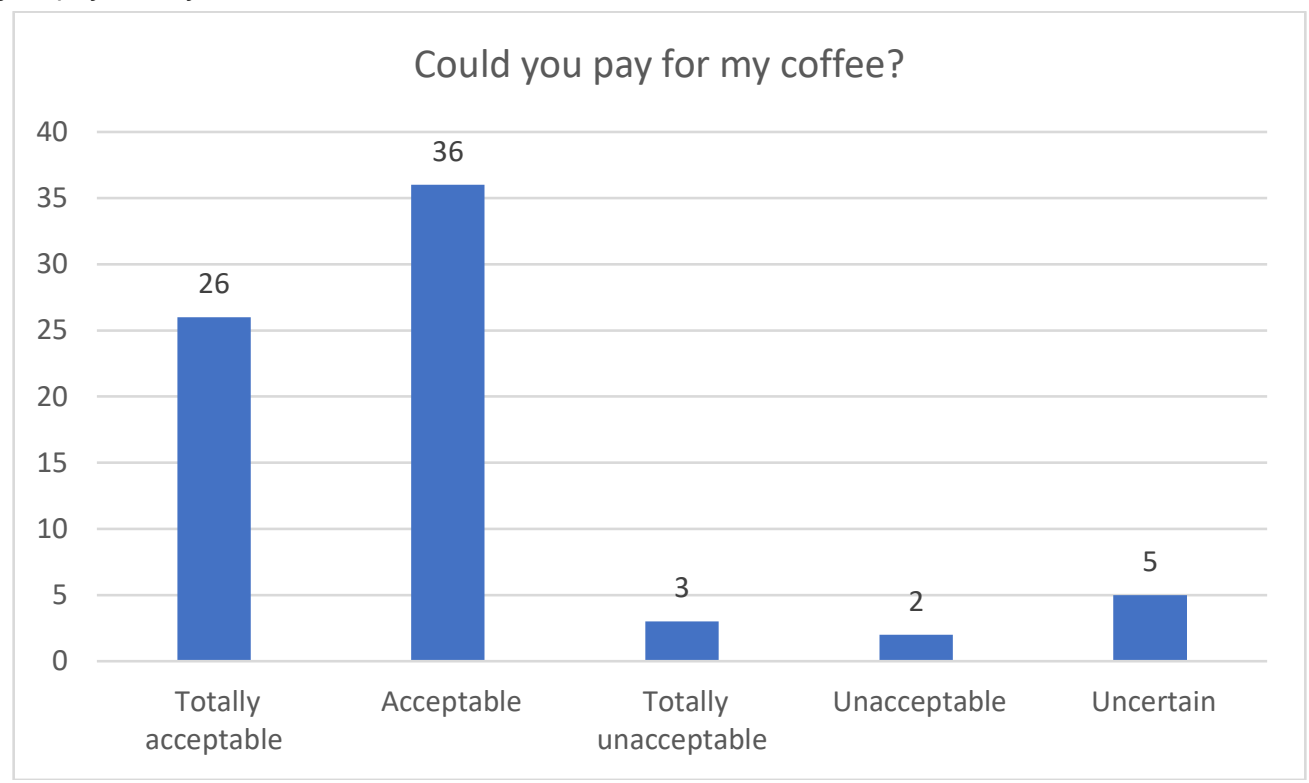

In figure 4.1, 26 of the respondents opined that the request is totally acceptable, 36 said it is acceptable and 3 of the respondents said it is totally unacceptable to make the request. 2 and 5 of the respondents argued that it is unacceptable and uncertain, respectively to make that request, with respect to the case in situation 1. (See appendix for situations)

Figure 4.2 could you pass me a piece of bread?

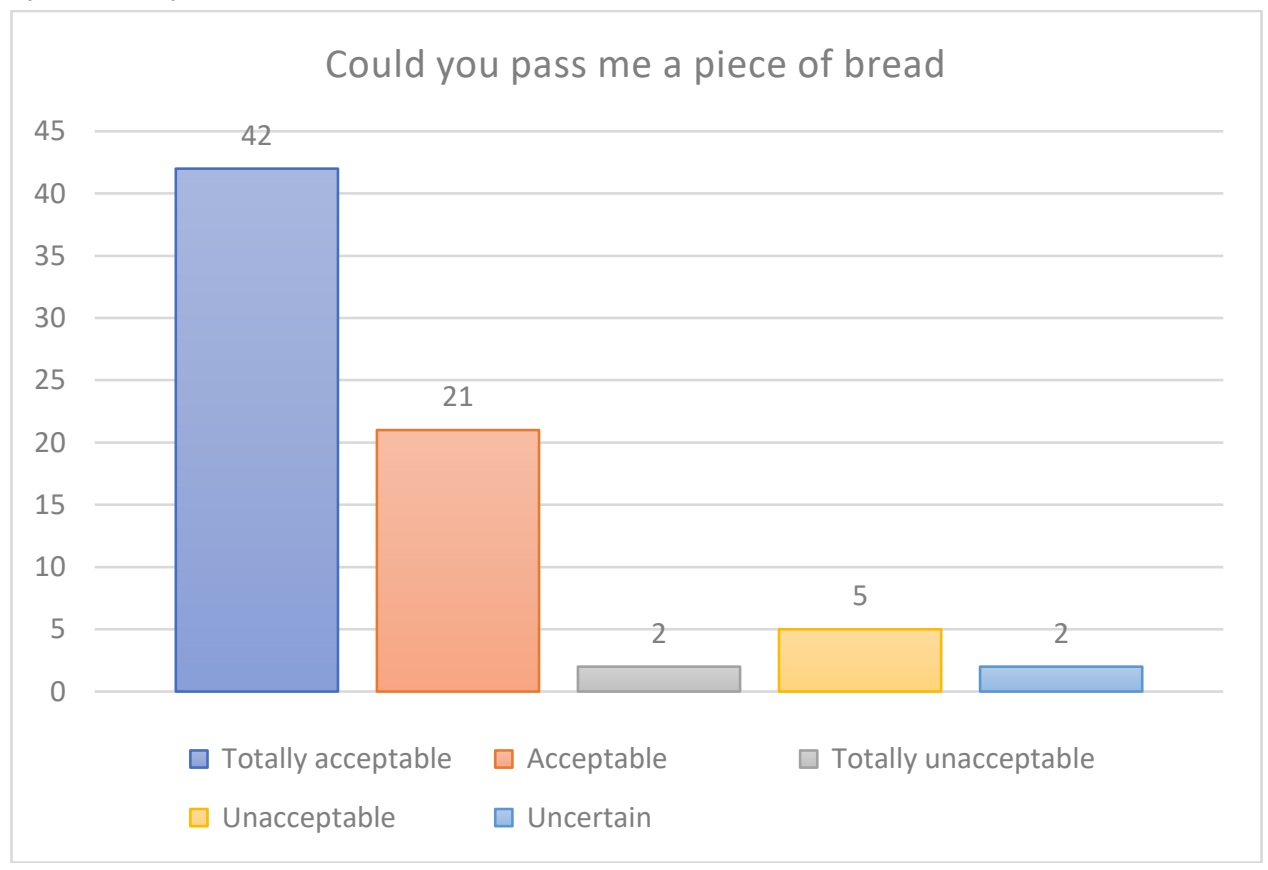

In figure 4.2, the "request" made was 'could you pass me a piece of bread'. The request made by the relative during the dinner was considered appropriate. 42 of the respondents supported that it is totally acceptable, 21 said it is acceptable. 2 of the respondents were uncertain, 2 respondents argued it is totally unacceptable whilst 5 respondents said it is unacceptable. 
Figure 4.3 would you mind help me, please?

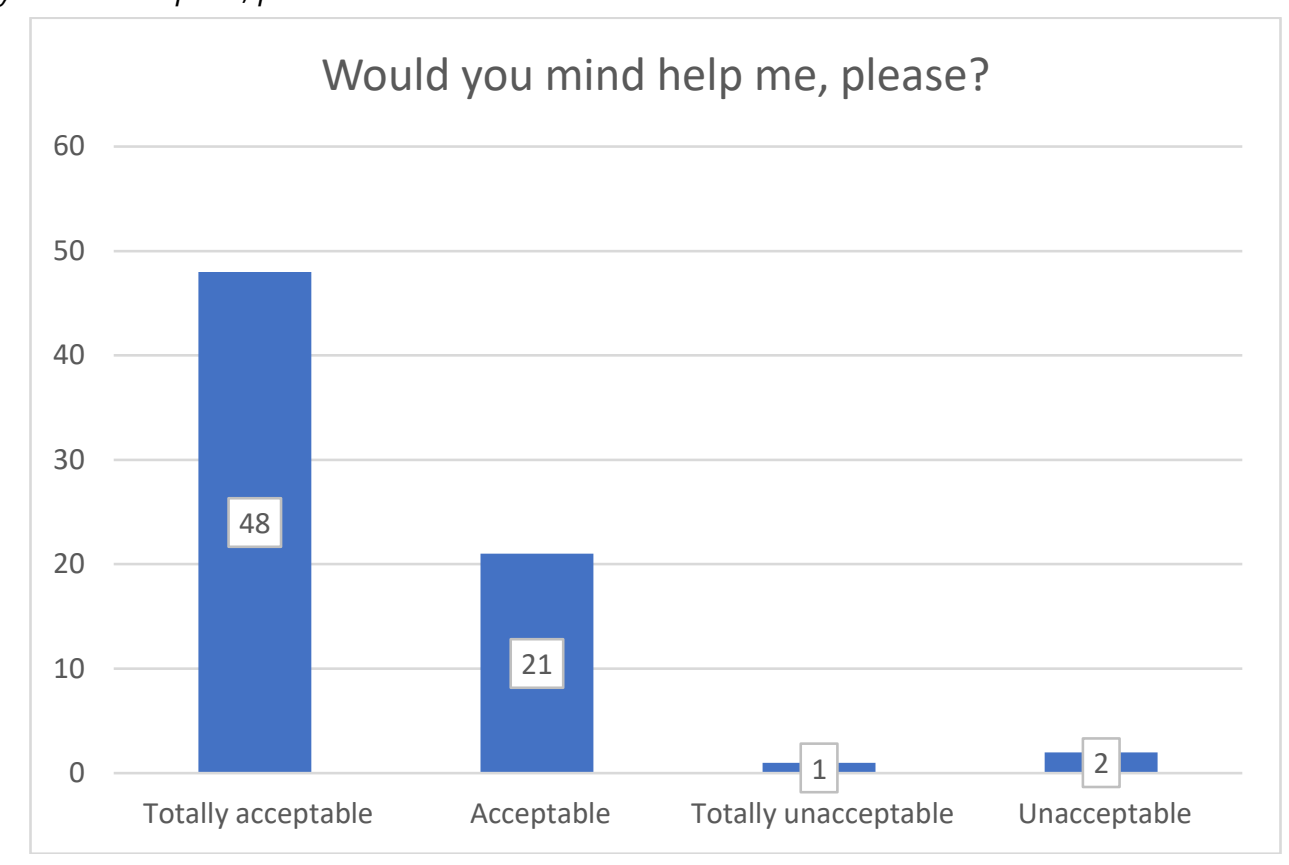

In figure 4.3, out of the 72 respondents, 48 ticked totally acceptable and 21 said the request is acceptable. None was certain about the request 'would you mind help me, please? Only one person argued that it is totally unacceptable and 2 also said it is unacceptable.

Figure 4.4 Wow it's a cool wrist watch, tell me more

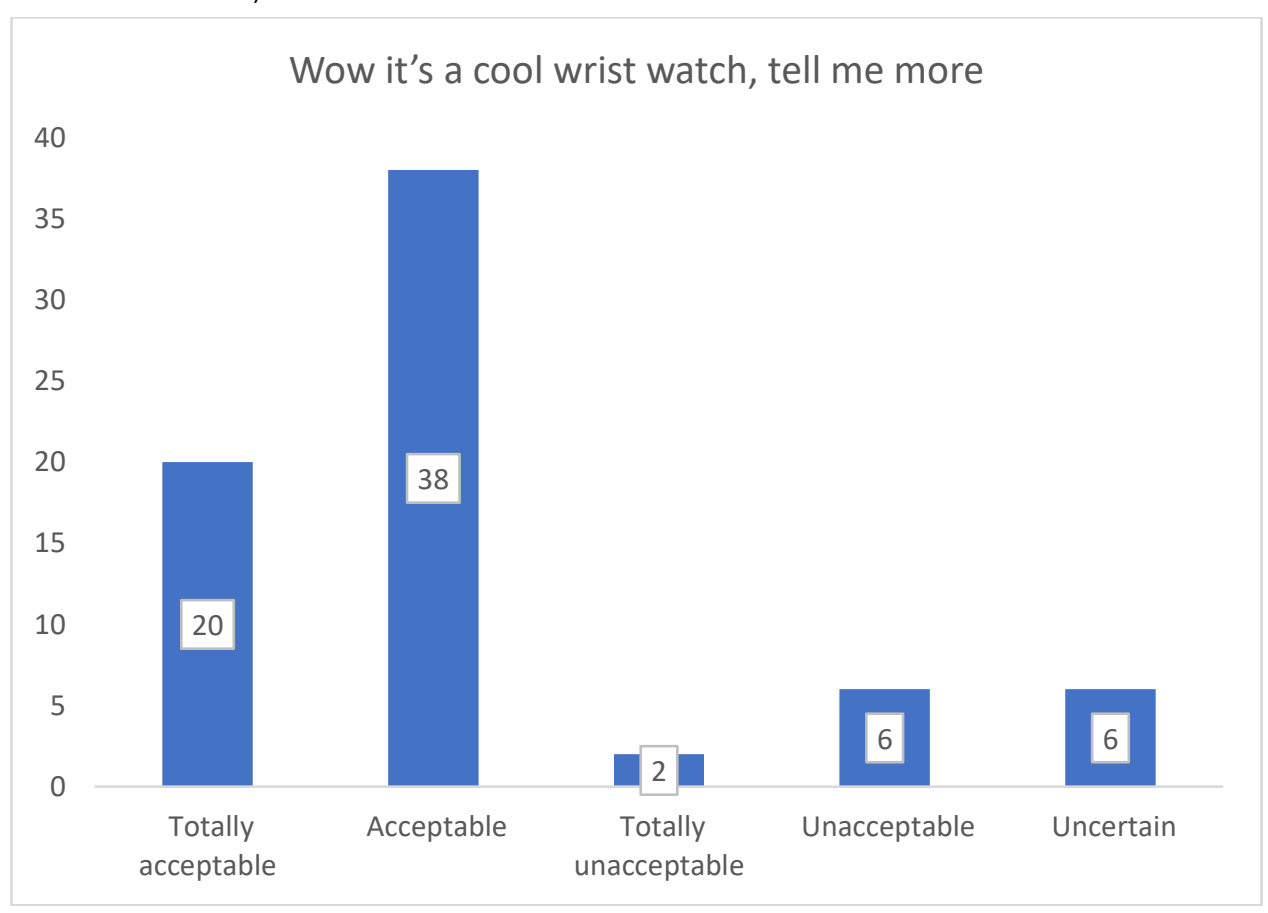

In response to situation 4 request, 'Wow it's a cool wrist watch, tell me more' as shown in figure 4.4, 20 of the respondents opined it is totally acceptable, 38 were of the view that it was acceptable and 2 of the respondents argued it is totally unacceptable. 6 people respectively ticked unacceptable and uncertain. 
Figure 4.5: Lecturer: Can we have dinner after class this evening?

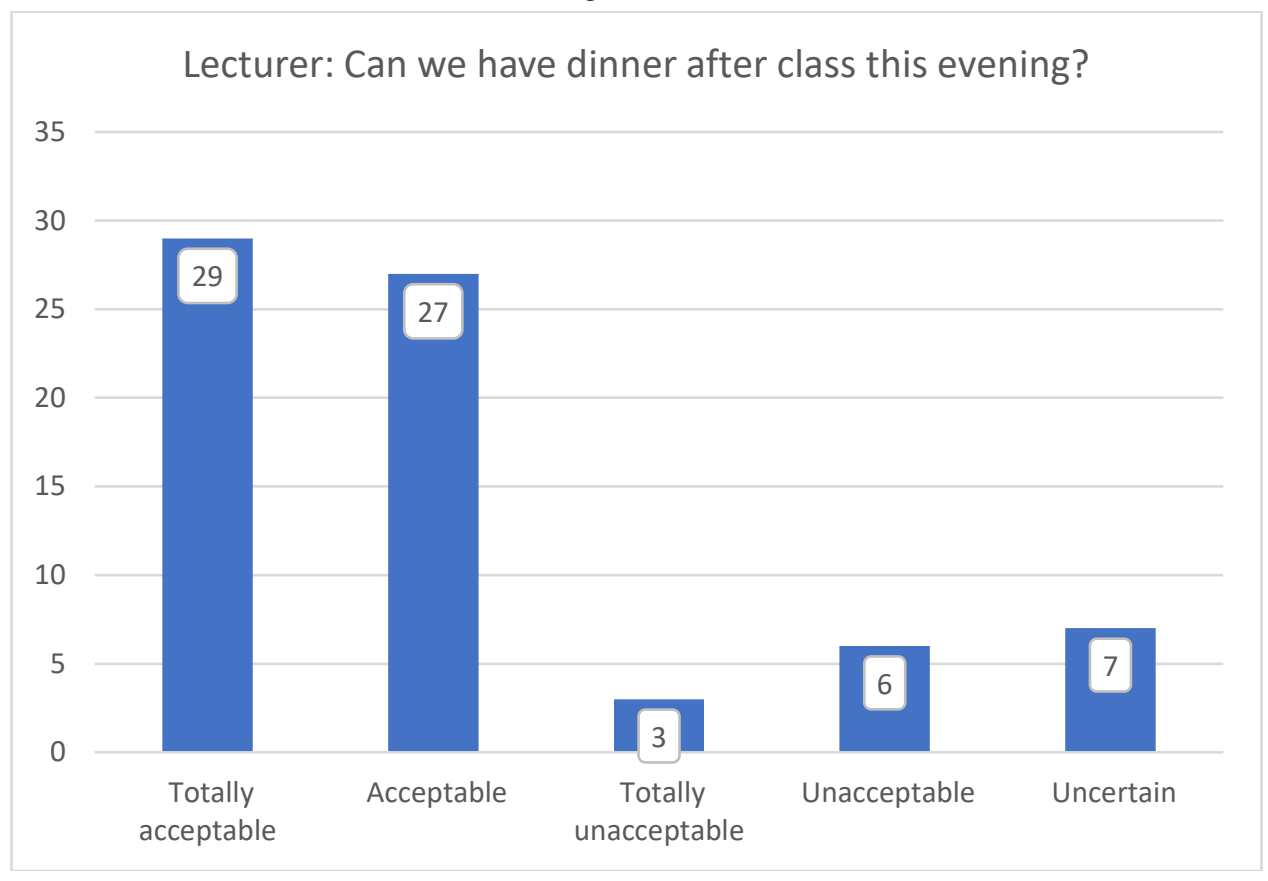

With respect to situation 5, Can we have dinner after class this evening? As seen in figure 4.5, 29 respondents said the request is totally acceptable, 27 responded acceptable, 3 also said it is totally unacceptable. 7 of the respondents were uncertain whether the request is appropriate and 6 of the participants admitted the request is unacceptable.

Figure 4.6 Can I borrow your notes, I missed a lecture and I want to make it up

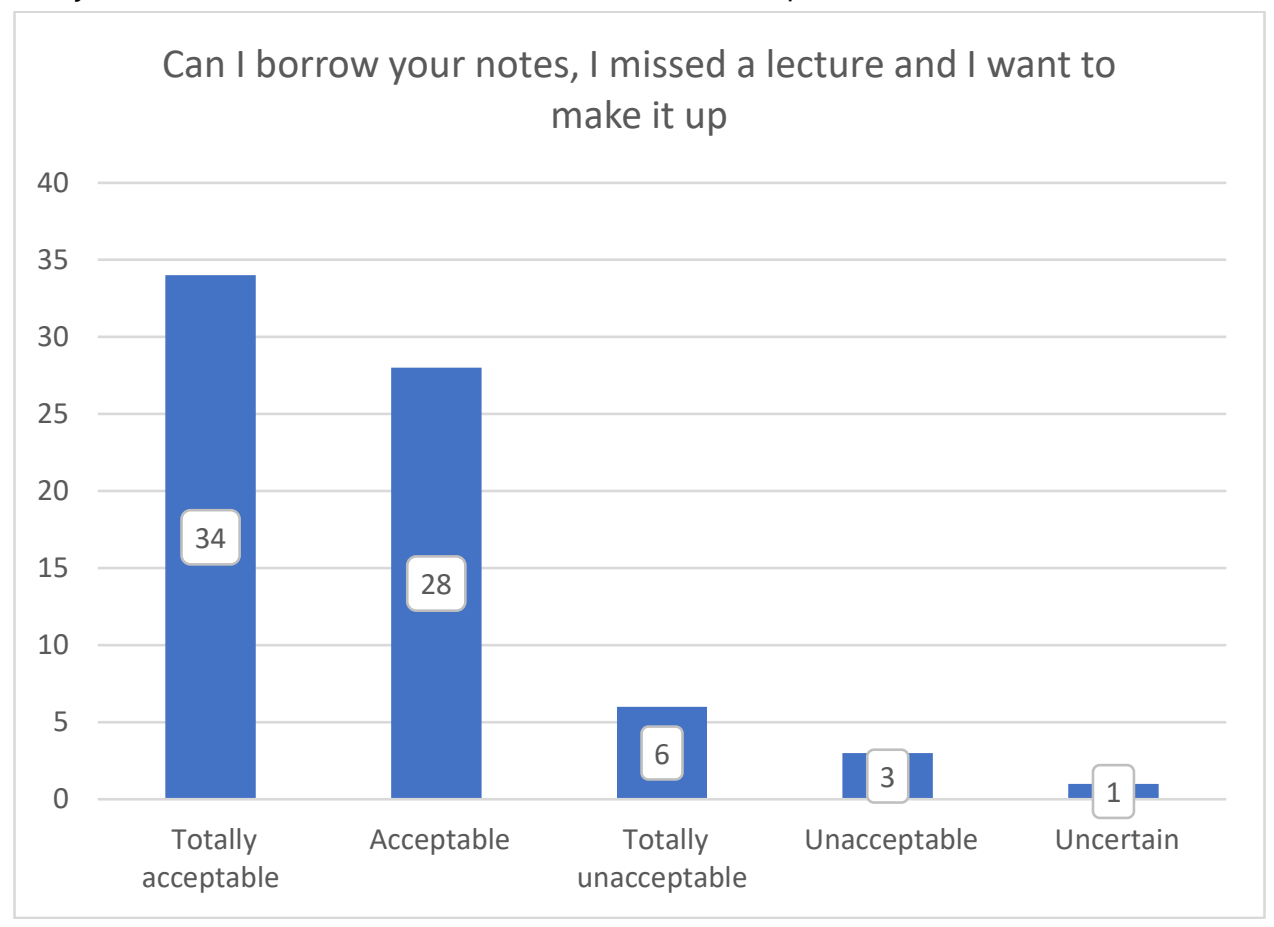

With respect to situation 6, 'Can I borrow your notes, I missed a lecture and I want to make it up', 34 respondents said it is totally acceptable, 28 also saw it as acceptable, 1 respondent was uncertain whilst 6 and 3 respondents argued is totally unacceptable and unacceptable respectively. 
Figure 4.7: I have tried very hard, could you do me a favor?

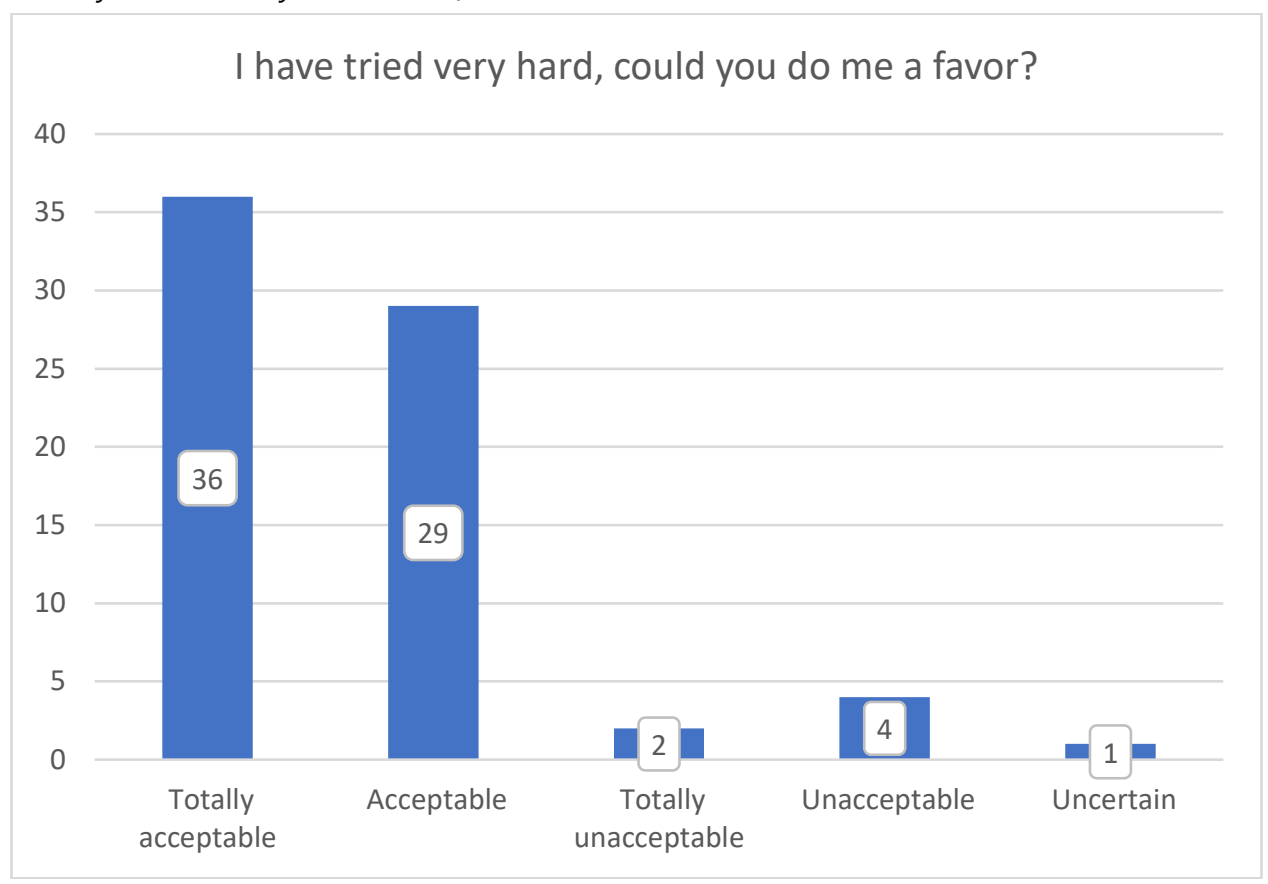

In situation 7, Excuse me, I couldn't find the MS101. I have tried very hard, could you do me a favor? Majority of the respondents considered the request as totally acceptable, 29 of the respondents said it is acceptable. Only 1 respondent was uncertain whiles 2 and 4 respondents said it is totally unacceptable and unacceptable respectively, to make that request.

Figure 4.8: Can I use yours?

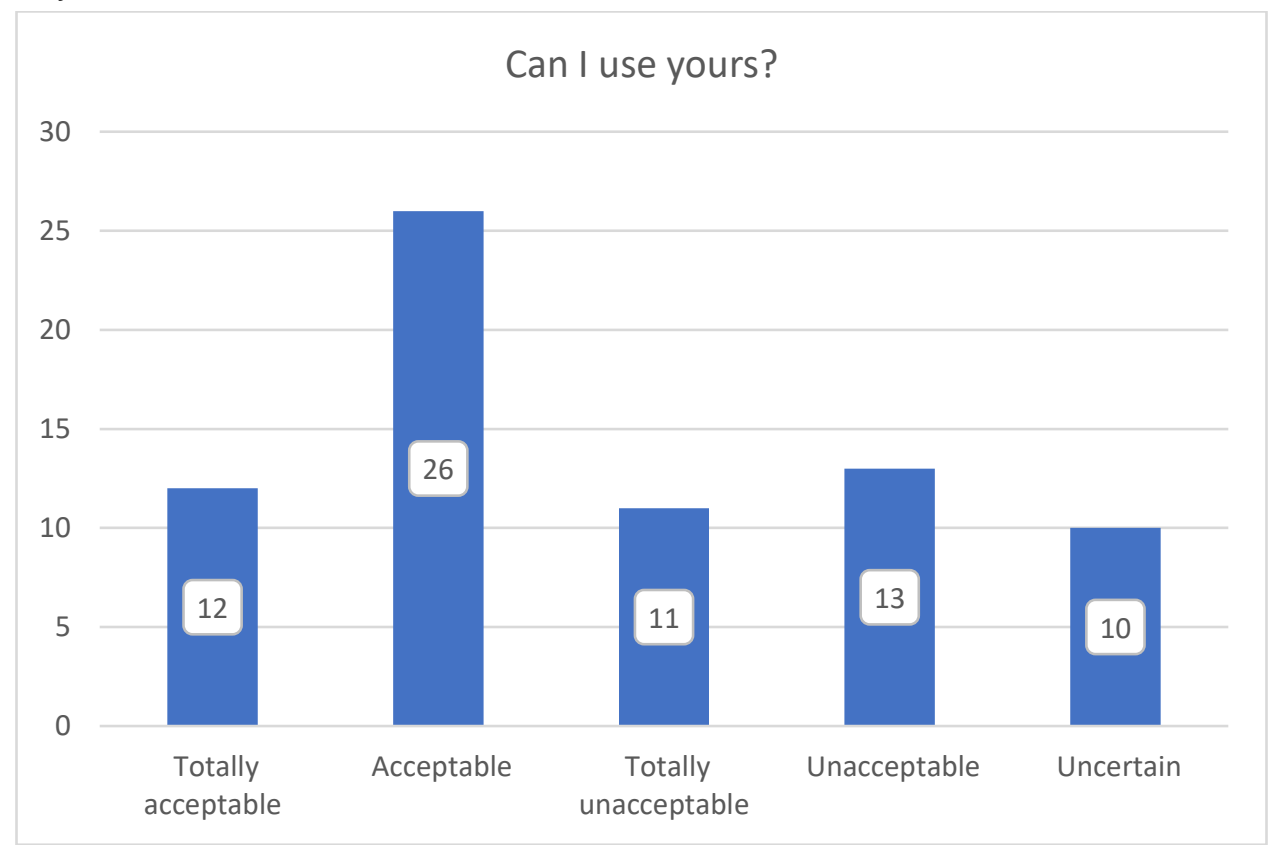

In situation 8, the request wants Jones to provide a credit card for a transaction, 'Jones, my credit card doesn't have money. Can I use yours? In such a situation, 11 respondents argued that it is totally unacceptable to make that request, 13 chose unacceptable and 10 of the respondents were uncertain. Meanwhile, 12 and 26 of the total respondents viewed the request as totally acceptable and acceptable respectively. 
Figure 4.9: could you show me the right directions?

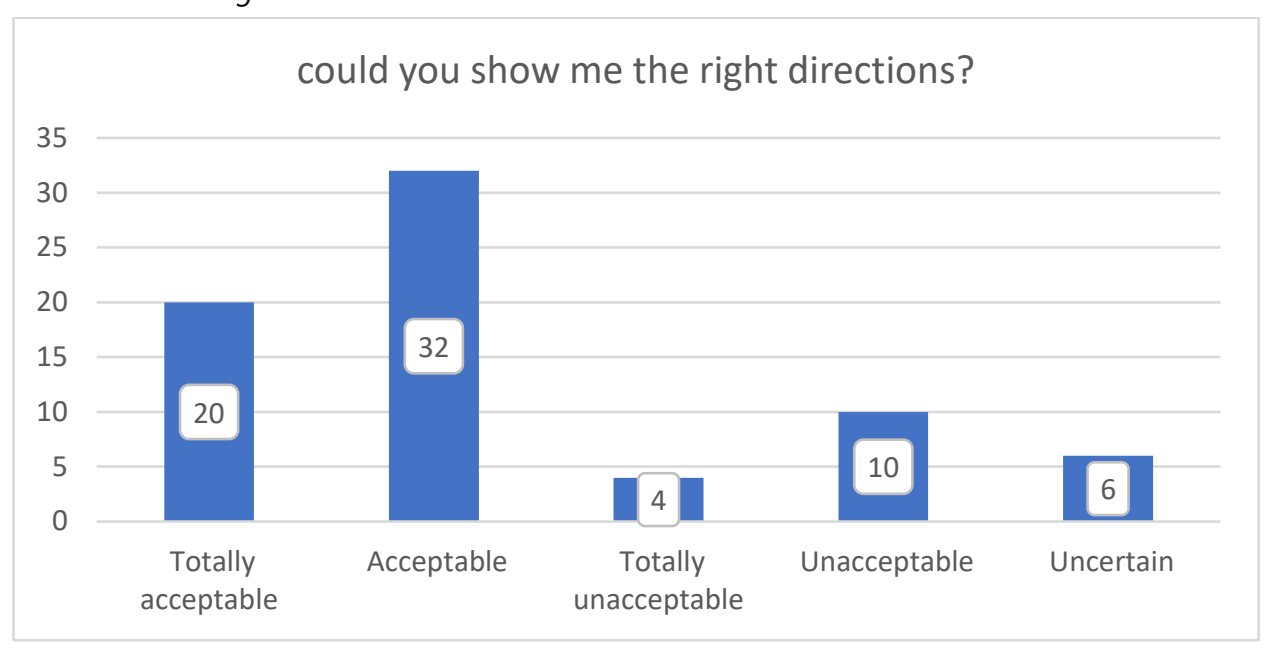

Excuse me miss, I'm going to St Annes hospital, could you show me the right directions?

In situation 9, as shown in figure 4.9, 65 of the respondents said the request is appropriate, that is totally acceptable. 2 of the respondents held the views that the request is totally not acceptable whilst 1 of the respondents was uncertain.

\subsection{Qualitative findings}

In situation 1 , the respondents gave almost the same response. $A, B, C, E$ and $F$, but the $D$ sound impolite. The request contains preparatory request strategies, that is (could you) which implies a low level of directness. In all the utterance given above, with the exception of $D$, the respondents showed polite responses and willingness to cooperate. The reason for this may be due to the fact that the request included tactful explanations or justifications for the strategies. Although D argued 'would stop buying' to express the fact that the request is not acceptable.

\section{Situation 1}

A Agree because people needs help

B It's ok...

C I will help him out. Things like that do happen

D Would stop buying

E Okay, no $p$

F Ok no problem Why because I may need help one day

According to the responses to the request strategy under situation two, could you pass me a piece of bread? In this case, the answers given were alike and their similarities were based on the presence of the politeness of the marker of the request. The request lacked politeness (please). In this situation, 5 of the respondents said is totally unacceptable and their low degree of acceptability was explained in terms of politeness. Once again, although preparatory request strategies are used (i.e. could you) there is no politeness in the request and this is one reason for not seeing them as absolutely acceptable. Please could you pass me a piece of bread rather than could you pass me a piece of bread? That is, preparatory request strategies seem to be more acceptable and appropriate than using the imperative. This generally is due to the transfer of L1 cultural impact in terms of socio-pragmatically on the L2.

\section{Situation 2}
A I shall do likewise as in (10) because that's good table manners.
B Please pass me the bread
C Kindly pass me the basket of bread.
D Can you pass me a piece of bread, please?
F Sure, why not? Courtesy begins at home 
In this situation 3, the request is so direct and polite. All the utterance given from $\mathrm{A}$ to $\mathrm{K}$ shows the necessity of the request. Their requests are made through preparatory strategies like would you mind' the maker is intended to represent an 'authentic' and 'real-world' context.

\section{Situation 3}

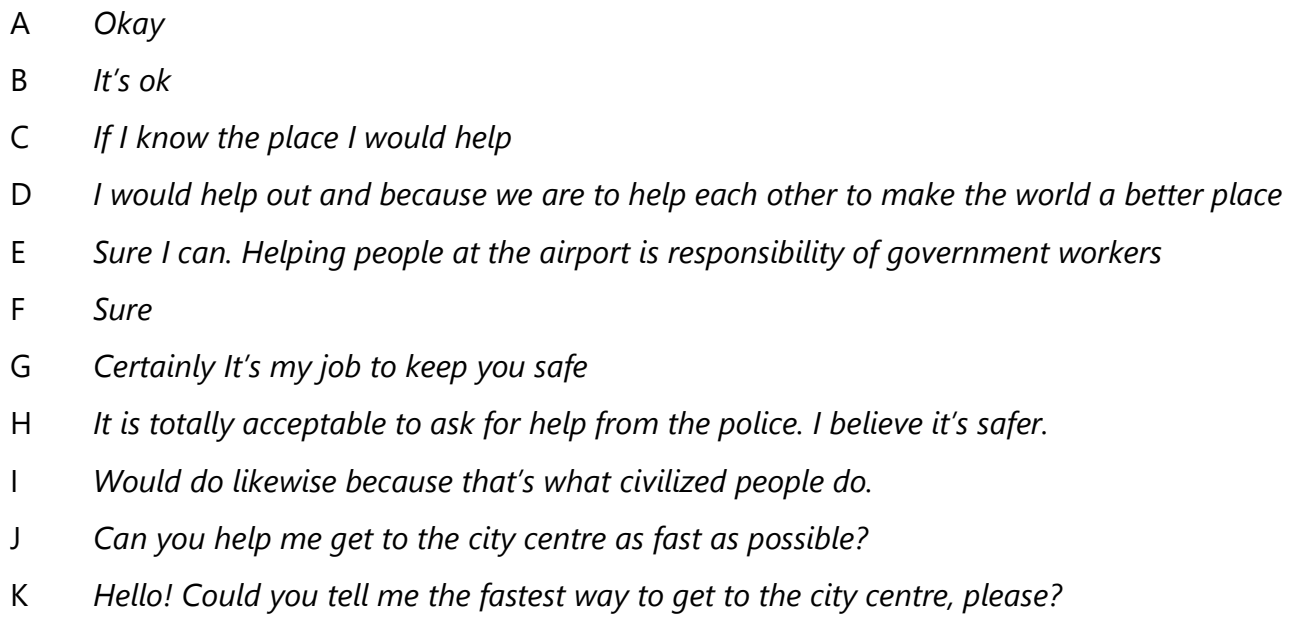

In situation four, the request initially showed commitment by expressing interest 'Wow'. Although the use of please was not present in the request, it has low tonation and the use of exciting request may force a hearer to provide laudable information for the maker. The appropriateness of the request is very necessary. Considering the scenario, the maker of the request use mood derivable strategy 'wow' since it happened among friends in the same dormitory. Sometimes the degree of relationship affects the politeness or directness of a request making the utterance same which usually not understood by third party. 'it's a cool wrist watch, tell me more' some of the respondents for example 'I' made a strong hint 'Why do you want to know more?' which looks more query respond. The L1 culture of Chinese may not be conventional for such 'want statement"

\section{Situation 4}

$\begin{array}{ll}\text { A } & \text { Acceptable } \\ \text { B } & \text { It's ok. } \\ \text { C } & \text { The same } \\ \text { D } & \text { Too costly } \\ \text { E } & \text { This is a Rolex, not a stopwatch, boy } \\ \text { F } & \text { Can you tell me more functions about the watch? } \\ \mathrm{G} & \text { Complement } \\ \mathrm{H} & \text { Thanks. I bought it from shop XYZ } \\ \text { I } & \text { Why do you want to know more? } \\ \mathrm{K} & \text { I would have said the same thing because first you praise him by showing interest in the watch then later you ask about the } \\ & \text { details of the watch } \\ \mathrm{L} & \text { How much did you buy it? } \\ \mathrm{M} & \text { Wow it is expensive wrist watch. Please tell more about it. This is a more polite way to ask. }\end{array}$

With respect to situation 5, Can we have dinner after class this evening? 29 respondents said the request is totally acceptable, 27 responded acceptable. The choice of request strategy in this context is influenced by typical tendencies in the relationship between the students and the Lecturer. On the other hand, the explicit, direct strategies appropriate for a certain situation may vary among different cultures (Blum-Kulka \& Olshtain, 1989; Yazdanfar \& Bonyadi, 2016). In this particular situation, the Lecturer used a direct strategy request 'can we have dinner after class this evening', showing concern for the students. From the utterance or response given below, all the respondents viewed the request as polite. 


\section{Situation 5}

A Yes sir, it's my pleasure to have dinner with you. This is because I should respond to the request in a way to show respect to him

B Not good refusing the invite of others unless with genuine concerns

C I would say the same thing

D I will say same

E Totally acceptable

F I think that some students may have something to do tonight and they will have no choice but to go out for dinner.

G Same

I For sure is a great opportunity to learn language too

With respect to situation 6, 'Can I borrow your notes, I missed a lecture and I want to make it up', the maker of the request used hedged performative 'can I' and continued with a strong statement. 'I missed a lecture and I want to make it up'. Also, the choice of the 'can' a modal, is an appropriate request strategy by the fact that the speaker is addressing a close friend. In this situation, the request could be reframed as (E) let me borrow your notes please, thank you. I prefer to say this since she's my classmate. The respondents see the request as appropriate and acceptable.

\section{Situation 6}

A Okay you can. Return it on time though

B I need the notes to copy, please

C yes, of course

D Can I borrow your notes, I missed a class and I have to make it up.

E Let me borrow your notes please, thank you. I prefer to say this since she's my classmate

F My pleasure

G I would say the same thing

H Totally acceptable

I Could you please borrow me the notes of the lecture because I missed it.

In situation 7, Excuse me, I couldn't find the MS101. I have tried very hard, could you do me a favour? In this request, the maker began by "excuse $m e$ " creating attention for the hearer, then continue with an explanatory or account, an appeaser, a structure that shows concern for the hearer or something to indicate that the speaker takes on responsibility. The maker ended the request by 'could you do me a favour?' the request is considered more appropriate and polite which imposes an obligation statement to the hearer. The findings from the survey revealed the responses from the respondents and it proved that the hearer could definitely not declined the request such as 'Certainly, It's actually my job'.

\section{Situation 7}

A $O K$

B Technically that would be my job to help

C Okay sure I can

D What favour?

E Certainly It's actually my job

F Totally acceptable. I would do same.

G Will do likewise because she's the Liberian and it is her job to help out.

H Kindly, help me find this book - MS101.

I I will say what favour can I do for you. Because I need to hear the person out and know how I can be of help to him or her

In situation 8, the request wants Jones to provide a credit card for a transaction, 'Jones, my credit card doesn't have money. Can I use yours? In such a situation, 11 respondents argued is totally unacceptable to make that request, 13 choose is unacceptable 
and 10 of the respondents were uncertain. Meanwhile, 12 and 26 of the total respondents viewed the request as totally acceptable and acceptable accordingly. The respondents did not see the request as polite although it involved preparatory request strategy 'Can I' but the sensitivity of the request as it involved L1 and L2 cultural difference. Hence, whereas some people may find necessary a politeness marker, an explanation for the request or a promise that they will have their money back, some others may not. In this scenario, the utterance in B Promises can be broken ?You have to show the money in cash first shows that the hearer needs assurance that he or she will have his/her money back.

\section{Situation 8}

A not $O K$

B Promises can be broken ?You have to show the money in cash first

C Errrmm...not sure

D Uncertain Some people don't like to pay their debts

E Buying the phone is not an emergency so I can wait till I have money. If I really need to then I have to tell my friend what I am buying with his card, the cost and when I intend to pay him back.

F Due to the sensitivity of credit cards, I would neither use mine to make purchases on behalf of anyone nor would I request such favor from anyone. There are too many security implications.

G Can you please help me with your credit card... mine doesn't have enough money now... I'll pay back later

Excuse me miss, I'm going to St Anne's hospital, could you show me the right directions?

Attention getters (excuse me) and the form of address (miss) renders the request so polite and direct using locution derivable structures (could you show). In this scenario, the use of (miss) as a form of address may be wrong since the female police officer marital status could not be known. See utterance I (I will say the same thing. However, I address her as officer instead of miss. This is because her marital status may not be known)

\section{Situation 9}

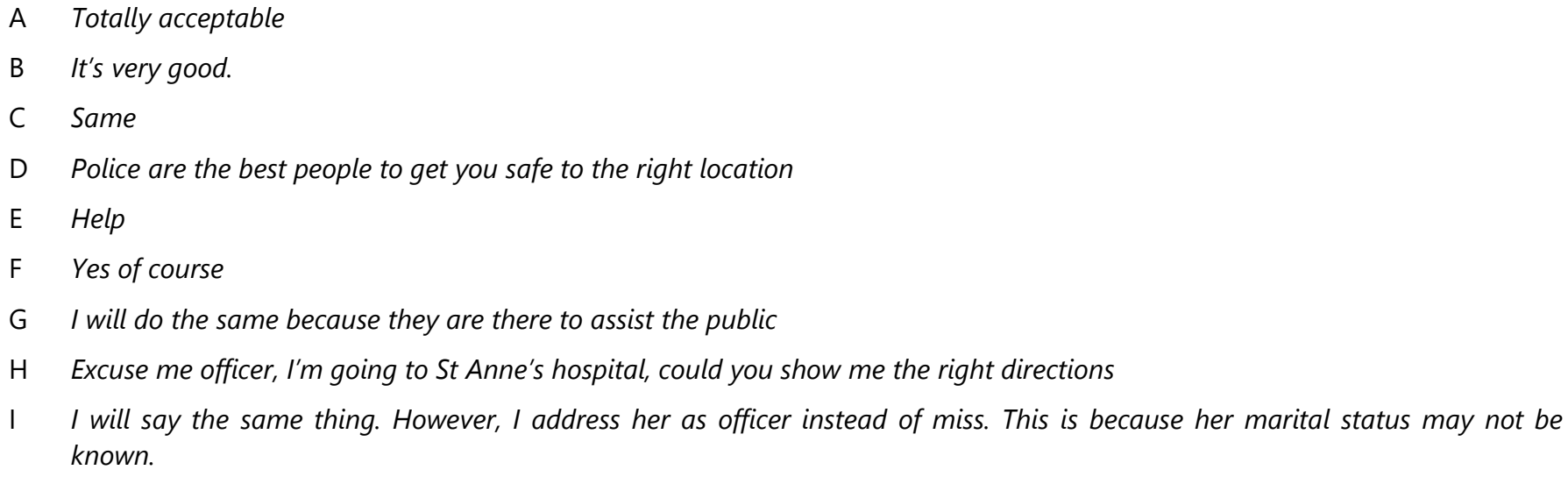

\subsection{Discussion of Results}

This section presents the discussion of the findings, the discussion addresses the two main research problems and relate the findings to other studies findings.

\subsection{Does knowledge of $L 1$ culture affect L2 pragmatic competence?}

The main objective is find out whether L1 culture affects learners' pragmatic competence of L2. In this study, the researcher used appropriate request to solicit for the intended responses that is the $\mathrm{L} 2$ pragmatic competence. The study provided a situation or scenario and gave appropriate request concerning all the request strategies necessary to provide precise pragmatic competence from the listener. In figure 4.1, the study posed a question for the respondents to determine whether is acceptable or not, 26 of the respondents opined that the request is totally acceptable, 36 said acceptable and 3 of the respondents said is totally unacceptable to make the request. 2 and 5 of the respondents argue in unacceptable and uncertain to make that request with respect to case in situation 1. (See appendix for situations. In situation 1, the respondents' utterance in similar views. $A$, $B$, $C$, $E$ and $F$, but the $D$ sound impolite. The request contains preparatory request strategies, that is (could you) which implies low level of directness 
Findings from previous studies support an overall positive L1 cultural effect on L2 pragmatic performance. In particular, the existing literature has found that compared to lower proficiency learners, higher proficiency learners are better at minimizing negative L1 transfer in situations where L1 and L2 patterns differ (e.g., Maeshilba, Yoshinaga, Kasper, \& Ross, 1996; Wannaruk, 2008). Moreover, more proficient learners are better at comprehending requests (Cook \& Liddicoat, 2002) and identifying different types of speech acts (i.e., request, suggestion, correction and offer) (Garcia, 2004). With regard to pragmatic competence, more competent learners have a larger repertoire of strategies to realize speech acts (e.g., Dalmau \& Gotor, 2007), and are able to use more target-like pragmalinguistic forms such as intensifiers (Dalmau \& Gotor, 2007), downgraders (e.g., Pinto, 2005) and contrastive markers (e.g., Geyer, 2007). However, high L2 proficiency does not guarantee a native-like pragmatic performance.

A similar cultural transfer of knowledge of L1 on L2 pragmatic is exhibited in situation 9. Excuse me miss, I'm going to St Annes hospital, could you show me the right directions? Attention getters (excuse me) and the form of address (miss) renders the request so polite and direct using locution derivable structures (could you show). The use of please, hi, hello, excuse me form of address and attention getters are transferred from L1 knowledge to L2 pragmatic competence. These are used to make appropriate requests for the hearer to employ correct pragmatic competence. In this scenario, the use of (miss) as a form of address may be wrong since the female police officer marital status could not be known. See utterance I (I will say the same thing. However, I address her as officer instead of miss. This is because her marital status may not be known). Although figure 4.9 shows 65 of the respondents said the request is appropriate, that is totally acceptable and acceptable. 2 of the respondents hold the views that the request is not totally acceptable while 1 of the respondents was uncertain.

Politeness can be interpreted as 'polite social behaviour' within a culture and within each particular culture, there are a number of different principles that guide politeness in social interaction (e.g. being tactful, generous, modest) (Yule, 1996). Therefore, it can be improved by increased proficiency which includes increased lexical, grammatical and discourse knowledge. In other words, L1 culture has positive effects on L2 pragma linguistics.

In figure 4.7, "Excuse me, I couldn't find the MS101. I have tried very hard, could you do me a favor?" The majority of the respondents considered the request as totally acceptable, 29 of the respondents said is acceptable. Only 1 respondent was uncertain whiles 2 and 4 respondents said is totally unacceptable and unacceptable to make that request.

However, the maker ended the request by 'could you do me a favor?' the request is considered more appropriate and polite which imposes obligation statement to the hearer. The findings from the survey revealed the responses from the respondents and it proved that the hearer could definitely not declined the request such as 'Certainly, It's actually my job' (utterance $E$, situation 7). Also, Geyer (2007) found that learners employed a greater number of lexical and grammatical markers to qualify their utterances when they had to adjust their previous opinions, and they were capable of using contrastive proficiency effect on L2 pragmatic competence expressions in conjunction with other discourse features, such as foregrounding main points of the utterance and putting the qualification segments in the background. These findings support the notion that higher proficiency learners have more lexical, grammatical and discourse knowledge, which allows them to outperform lower proficiency learners on pragmatic production at the discourse level. However, proficiency effects vary depending on different types of target pragmalinguistic forms, such as speech acts of different degrees of directness and conventionality. For example, Félix-Brasdefer (2007) showed a decline in the production of direct requests but an increase in the production of conventional indirect requests, and no significant difference in the production of unconventional indirect requests from learners of $L 1$ to $L 2$.

Bardovi Harlig (2008) showed that cultural knowledge only had a positive effect on recognition but not on the production of formulaic expressions. Formulaic expressions are fixed or semifixed lexical strings that can serve pragmatic functions in situations. Therefore, the acquisition of formulaic expressions is similar to that of vocabulary knowledge, showing a gap between comprehension and production. These findings suggest that modalities of pragmatic performance should be taken into account when we discuss pragmatic competence effect on L2 pragmatics. Figure 4.8 places more emphasis on recognition. In situation 8 , the request wants Jones to provide a credit card for a transaction, 'Jones, my credit card doesn't have money. Can I use yours? In such a situation, 11 respondents argued is totally unacceptable to make that request, 13 choose is unacceptable and 10 of the respondents were uncertain. Meanwhile, 12 and 26 of the total respondents viewed the request as totally acceptable and acceptable accordingly. The respondents did not see the request as polite, although it involves preparatory request strategy 'Can I' but the sensitivity of the request as it involves L1 and L2 cultural difference. Hence, whereas some people may find necessary a politeness marker, an explanation for the request or a promise that they will have their money back, some others may not. In this scenario, the utterance in B Promises can be broken ?You have to show the money in cash first shows that hearer needs assurance that he or she will have his/her money back.

In figure 4.2, the request was 'could you pass me a piece of bread', appropriateness of the requests made by the relative during the dinner was consider appropriate. 42 of the respondents supported that it is totally acceptable, 21 acceptable. According to 
the respondents to the request under situation two, could you pass me a piece of bread? In this case the answer given was alike and their similarity is based on the presence of the politeness of the marker of the request. The request lacks politeness (please) in this situation 2 which has an important role in request strategies. In situation 5, respondents said it is totally unacceptable and their low degree of acceptability was explained in terms of politeness. Once again, although preparatory request strategies are used (i.e. could you) there is not politeness marker and this is one reason for not seeing them as absolutely acceptable. Please could you pass me a piece of bread rather than could you pass me a piece of bread?

In summary, culture has positive effects on L2 pragmatic competence, but these positive effects depend on the nature of pragmatic target features such as different types of speech acts (e.g., Cook \& Liddicoat, 2002; Félix-Brasdefer, 2007), and modalities of pragmatic performance (i.e., comprehension and production) (e.g., Bradovi-Harlig, 2008, 2009). The other aspect of pragmatic competence, namely, sociopragmatics, on the other hand, refers to the social aspect of pragmatic competence, which involves evaluation of social factors embedded in task situations such as interlocutors' social status, social distance and power relationship. It seems that compared to pragmalinguistics, socio pragmatics is less susceptible to the influence of proficiency because it does not directly focus on particular linguistic forms. For example, Takenoya (2003) showed that there was no significant difference in the production of address forms across proficiency levels, because higher proficiency learners did not have more native-like awareness of social variables reflected in Feng Xiao task situations (e.g., addresses' social status and social distance between interlocutors). Similarly, Niezgoda and Roever (2001) found that high proficiency L2 English learners' awareness of pragmatic errors was lower than low proficiency learners'.

In figure 4.5, 'Can we have dinner after class this evening? In this scenario, 29 respondents said the request is totally acceptable, 27 responded acceptable, 3 also said is totally unacceptable. In this particular situation, the lecturer used a direct strategy request 'can we have dinner after class this evening' showing concern for the students as shown in situation 5 . One possible reason is that $\mathrm{L} 2$ learners may need more time to realize differences between $\mathrm{L} 1$ and $\mathrm{L} 2$ socio pragmatic norms and make their decisions to conform to or resist the target norms. L2 learners may consciously choose to diverge from the target norms because they may want to maintain their foreign identity (e.g., Davis, 2007; Kim, 2014) or because the target norms do not match their perceived self-image as a second language speaker (e.g., LoCastro, 2001, 2012). In summary, previous studies have found that more proficient learners have more L2 pragmalinguistc forms to perform pragmatic functions, but proficiency effects vary depending on the nature of target pragmatic features. With regards to sociopragmatics, higher proficiency learners do not necessarily have better knowledge of target social norms, which is essential to a native-like pragmatic performance.

\subsubsection{Do a request and its response contribute to pragmatic failure?}

The request strategy to use, either direct or indirect, contribute greatly to pragmatic failure. For example, in situation 9 where the maker of the request used (miss) to refer to a female policer officer. The identity of the police woman could be wrong, thereby leading to pragmatic failure. Although the use of excuse seeks the attention of the hearer but as soon as is followed by miss it could change the intended meaning. Excuse me miss, I'm going to St Annes hospital, could you show me the right directions? According to Bujan (2016) Pragmatic failure is the "inability to recognize the force of the speaker's utterance when the speaker intended that this particular hearer should recognize it.

Pragmalinguistic failure is "basically a linguistic problem, caused by differences in the linguistic encoding of pragmatic force", whereas sociopragmatic failure "stems from cross-culturally different perceptions of what constitutes appropriate linguistic behaviour" (Thomas, 1983, p. 99). The first one "occurs when the pragmatic force mapped on to a linguistic token or structure is systematically different from that normally assigned to it by native speakers" and it may arise either from teaching-induced errors or from pragmalinguistic transfer (i.e. inappropriate transfer of speech strategies and utterances from the L1 to the L2) (Thomas, 1983). As for the second typology, it refers to the speaker's inability to adapt the language to certain judgments concerning the social conditions of the context (e.g. size of imposition, cost/benefit, social distance, relative rights and obligations) (Thomas, 1983, p. 104). Whereas pragmalinguistic failure is "fairly easy to overcome", sociopragmatic failure is "much more difficult to deal with" (Thomas, 1983, p. 91 


\section{Conclusion and Recommendations}

\subsection{Conclusion}

The study developed a research tool aimed at studying the pragmatic competence of Chinese learners of EFL through the performance of requests and response. Those speech acts were evaluated in terms of appropriateness by the Chinese respondents and it was found out that whereas some utterances were considered clearly either 'unacceptable' or 'totally acceptable', some others seemed controversial. This led us to the conclusion that L1 culture may influence the way they understand what is told and, consequently, the way the speaker made the request. Hence, pragmatic competence in the foreign language is not the only reason for pragmatic failure to occur. Getting answers from our Chinese respondents to the same situations in their L1 would help us to check if the inappropriate utterances were also so in their native language and verify whether their non-acceptability is due to low levels of pragmatic competence or to personal issues. In any case, most of the utterances did not show clear evidence of pragmatic failure, which indicates that, overall, our Chinese students have a reasonable level of pragmatic competence

In this study, the researcher stretched on the knowledge of L1 culture and its effects on L2 pragmatic competence. The respondents who were mainly Chinese students constructively applied ideas, manners, and already knowledge to respond to the request. For example, a more demanding request would generally be asked in a more indirect and polite manner as opposed to minor favor, such as asking a person, 'Could you pass me a piece of bread?. In interaction among friends, more casual requests would be employed, compared to requests from acquaintances, presuming that both situations regard the same request. On the other hand, the explicit, direct strategies appropriate for a certain situation may vary among different cultures (Blum-Kulka \& Olshtain, 1989; Yazdanfar \& Bonyadi, 2016).

Jenny Thomas (1983) focuses on the former sense of pragmatic failure and differentiates two types: pragmalinguistic and sociopragmatic failure, two terms with which we are already familiarized.

\subsection{Recommendations}

Base on the findings from the study, the researcher made the following recommendations; Teachers or instructors teaching English as a second language (ESL) should make use of appropriate request strategy to improve pragmatic competence.

Learners should try to understand request in their local dialect, transfer the ideas and respond to their best of knowledge using the $L 2$ constructively to avoid a lot of pragmatic failures.

Instructors should engage learners of English as a second language in a lot of appropriate request strategy to build learners competence and ability to understand situations in a different environment.

Moreover, English as a second language is learned through instructions. It seems logical that pragmatic competence in the $\mathrm{L} 2$ will need special attention in the foreign language classroom. Therefore, educational authorities have to deal with how foreign language teachers can approach pragmatic competence in their lessons to raise students' awareness of linguistic and cultural pragmatic issues, which are necessary for them to understand that different communities are governed by different social norms and to avoid pragmatic failure.

The study recommends that teachers should use familiar scenarios to create request in a polite manner. This will help the hearer to apply or transfer more L1 pragmatic competences

\subsection{Suggestions for Future Research}

Since the present study investigated L2 pragmatic development within the prism of requests and its response, it would be necessary to widen the scope of the investigation to include other potentially troublesome speech acts, such as refusals, apologies, complaints, and so on.

For future studies, it could be considered to use a DCT in dialogue form, written or by using role-playing, which may produce different forms of requests. Finally, the results of this study, specifically the low variability of them, might be taken into consideration when planning lessons for students in order to provide them with opportunities to develop their pragmatic competence in L2 English.

\subsection{Limitations}

It is inevitable that the study has some limitations. One limitation is that the sample size is small. Although the researcher expected a higher number of respondents, only 72 Chinese students participated. They are mainly limited to graduate students at the Nanjing Tech University. Due to the limitation of the scope of the present study, the statistical results obtained from the questionnaire analysis might not be generalized to the whole target population. Also, the modified DCT applied in this study is still not ideal enough to elicit responses similar to those in natural conversation settings. 
Although it has been modified to include open-ended questions, it is still not as interactive as the real conversations in natural settings. In the pilot study, many interviewees expressed that their request strategy depended to a large extent on what response they would obtain from the hearer after some tentative questions, such as information about their willingness to help or their availability. To some extent, participants' consciously written responses to the questionnaire might be quite different from their unconscious oral responses in natural conversation settings.

\section{References}

[1] Baron, A. (2003). Acquisition in Interlanguage Pragmatics: Learning how to do things with words in a study abroad context. Amsterdam/Philadelphia: John Benjamins Publishing Company.

[2] Blum-Kulka, S., \& Sheffer, H. (1993). The Metapragmatic Discourse. Interlanguage pragmatics, 196.

[3] Blum-Kulka, S., Danet, B., \& Gherson, R. (1985). The language of requesting in Israeli society. In Language and social situations (pp. 113139). Springer, New York, NY.Byon, A. (2004). Sociopragmatic analysis of Korean requests: pedagogical settings. Journal of Pragmatics, 46, 1673-1704.

[4] Canale, M. \& Swain, M. (1980). Theoretical bases of communicative approaches to second language teaching and testing. Applied Linguistics 1, 1-47.

[5] Ellis, R. (1994). The study of second language acquisition. Oxford: Oxford University press

[6] Erickson, F. (1984). Rhetoric, anecdote, and rhapsody: Coherence strategies in a conversation among black American adolescents. In D. Tannen (Ed.), Coherence in spoken and written discourse (pp. 81 - 154). Norwood, NJ: Ablex. Failure. Studies in Second Language Acquisition, 8, 165-179.

[7] Fraser, B. (2010). Pragmatic competence: The case of hedging. New approaches to hedging (pp. 15-34). Bingley: Emerald. Retrieved from http://www.bu.edu/sed/files/2010/10/2010-Pragmatic-Competence-The-Case-of-Hedging.pdf

[8] Geluykens, R. (2007). On methodology in cross-cultural pragmatics. In B. Kraft \& R. Geluykens (Eds.), Cross-cultural pragmatics and interlanguage English (pp. 21-72). München: Lincom Europa.

[9] Hassall, T. (1997). Requests by Australian Learners of Indonesian, Unpublished PhDdissertation, Australian National University.

[10] Hymes, D. H. (1972). On Communicative Competence. Sociolinguistics, In: J. B. Pride \& Holmes, J. (Ed). Sociolinguistics. Harmondsworth: Penguin.

[11] In J. P. Forgas (Ed.), Language and social situation (pp. 113-141). New York: Springer

[12] Kılıçkaya, F. (2010). The Pragmatic Knowledge of Turkish EFL Students in Using Certain Request Strategies. Gaziantep University Journal of Social Sciences, 9(1), 185-201.

[13] Kinginger, C. (2011). Review of the book Interlanguage Pragmatic Development: The study Abroad Context, G. Schauer. Applied Linguistics, 32(5), 572-574.

[14] Leech, G. (1983). The principles of pragmatics. Harlow: Longman

[15] Levinson, S. (2000). Presumptive Meanings: The theory of Generalized Conversational Implicature. Cambridge, MA: MIT Press Linguistics, 1, 129-157.

[16] Mey, J. (1993). Pragmatics: An introduction. Oxford: Blackwell

[17] Newmeyer, F. (2004). Typological evidence and universal grammar. Studies in Language, 28, 527-48.

[18] Schmidt, R. W., \& Richard, J. C. (1980). Speech acts and second language learning. Applied

[19] Thomas, J. (1995). Meaning in interaction: An introduction to pragmatics. New York: Verlag.

[20] Wang, Y. 2010. Application of pragmatics theories in college English teaching. Language and Literature Learning, 7, p. 127-128.

[21] Zhang, Y. (1995a). Strategies in Chinese requesting. In Gabriele Kasper. (Ed.), Pragmatics of Chinese as native and target language. Honolulu, Hawai'i: University of Hawai'i, Second Language Teaching \& Curriculum Center, 23-67. (In Chinese)

[22] Zhang, Y. (1995b). Indirectness in Chinese requesting. In Gabriele Kasper. (Ed.), Pragmatics of Chinese as native and target language. Honolulu: University of Hawaii Press, 71-118. (In Chinese) 